\title{
Surgical Infections \& Rule of Antibiotics
}

\section{Amer Hayat Khan*}

Department of Clinical Pharmacy, School of Pharmaceutical Sciences, Universiti Sains Malaysia

Data regarding risk factors for surgical procedure and usage of antibiotics are essential to prevent and treat Surgical Site Infections (SSI) [1]. Prophylactic use of antibiotics has been found helpful in reduction of such morbidities. It is a well accepted intervention in numerous surgical procedures as well. However, there are contraverses with the fact that the medical fraternity administers antibiotics haphazardly. Evidence based guidelines, and boundaries between prophylactic and therapeutic antibiotic administration are often ignored or disregarded. Literature reveals inappropriate antibiotic prophylaxis during early 1970s in majority of hospitalized patients $[2,3]$. In this context, indication for prophylaxis, and selection and duration of antibiotics were reported to be irrelevant. However, a better understanding and selection of antibiotic prophylaxis gradually developed. Researcher established general principles that addressed adverse effects of prolonged chemoprophylaxis. These principles lead surgeons with a notion that antibiotics are not a substitute for suboptimal outcome [4].

Rate of inappropriate antibiotic administration in elective colorectal surgery was reported to be $73 \%$ in nationwide Malaysian survey. The survey also identified area of gap in published national guidelines for antibiotic administration [5]. Although antibiotic prophylaxis is considered important in surgical procedures [6], inappropriate use of antibiotics is however being practiced in $25-50 \%$ of general elective surgeries [7-9]. Meanwhile, beside the fact that appendectomy does accompany $1-5 \%$ of SSI with it $[1,10,11]$, efficacy of antibiotic prophylaxis in patients undergoing appendectomy has been observed in several randomized and observational studies [12-17]. Findings from these studies suggest that appropriate use of antibiotics may reduce the risk of SSI following appendectomy by $40-60 \%$. Moreover, prophylactic use of antibiotics shortens the hospital stay as well. It is further elaborated that prevention of wound infection is associated with faster return to normal activity after discharge from hospital [1820].

Preoperative use of antibiotics and surgical technologies are highly valuable aspects of care in major surgical procedures. However, it is emphasized that preventive measures for SSI are more or less unrealistic. This notion is because of certain unchangeable risk factors such as comorbid diseases, prolong hospital stay and type of surgery [18-21]. Hence, a patient should be provided with abolition of all preventable infections by adopting evidence based actions. The Center for Disease Control (CDC) recommends prophylactic use of antibiotic for either surgical incision or wounds [18]. If the antibacterial regimen does not sufficiently cover all microorganisms, supplementary prophylaxis regimen should be considered e.g. provided the risk of methicilin resistant Staphylococoous aurus (MRSA) is highly susceptible and the prescribed regimen does not cover MRSA, vancomycin may be recommended.

Variation in the practice of surgical antibiotic prophylaxis is quite evident in Malaysia. Lim and colleagues conducted a study in seven hospitals of Malaysia and found that different antibiotic regimens were used for among various surgical procedures. Majority (70\%) of antibiotics were prescribed to patients where such prophylaxis was probably not necessary. Moreover, when prescribed, antibiotics were given for durations that were longer than necessary. Lim and colleagues emphasized implementation of guidelines so as to improve the practices of health care professionals. They further highlighted standardization of surgical prophylactic regimens in context of cost reduction and emergence of antibiotic resistance [22]. Meanwhile, a survey conducted among the Ministry of Health Oral Surgery units showed a wide variation in the choice of antibiotics used for surgical prophylaxis. Extensive use of metronidazole and broad spectrum antibiotics (Ampicillin, Amoxycillin, $2^{\text {nd }}$ and $3^{\text {rd }}$ generation Cephalosporins etc) was profoundly observed in it [23]. Another survey carried among Dental Officers in Pahang and Malacca states of Malaysia revealed that a significant number of Dental Officers did not understand the meaning of antibiotic prophylaxis. Respondents of the survey were further found to be unaware with the drug and regimen usage [23]. Apart from abovementioned issues, Mazza reported the economic burden of common antibiotics that were prescribed prophylactically for infection in Malaysia. Analysis was made on the basis of cost of selected antibiotic and their therapeutic group which was further compared on surgical procedure $[21,24]$. They found that long acting antibiotics affected the cost to therapy.

The ideal duration of post-operative antibiotics is not clearly defined although most studies report that there is no additional benefit when antibiotic prophylaxis was continued beyond 24 hours [1,15,25-26]. In context of hospital costs related with surgical complications, Dimick and colleagues established that the increased cost was $\$ 1398$ per patient for infectious complications; $\$ 7789$ per patient for cardiovascular complications; $\$ 52,466$ per patient for respiratory complications; and $\$ 1810$ per patient for thromboembolic complications [27]. However, it seems inappropriate to evaluate antimicrobial use based on cost alone. Inappropriate usage should also bear over- and under-usage of an antibiotic, burden of mortality rate, the resources consumed for development of new chemotherapeutic agents against resistant microorganism [28]. Hence, the exact cost of prophylaxis therapy should be viewed in consideration with above mentioned outcomes.

On the other hand additional length of stay and charges, and increase in mortality rate due to patient safety events in the hospital can be attributed to postoperative complications [29]. Recent analysis of data from the Veterans Health Administration (VA) National Surgical Quality Improvement Project (NSQIP) confirmed that occurrence of any complication within 30 days of postoperative duration reduced median patient survival by $69 \%$ [30]. Such immense reduction in survival

*Corresponding author: Amer Hayat Khan, Department of Clinical Pharmacy, School of Pharmaceutical Sciences, Universiti Sains Malaysia, 11800 Penang, Malaysia, Tel: 006-014-9227580; Fax: 00604657 0017; E-mail: amerhayat@ymail.com

Received February 15, 2013; Accepted April 16, 2013; Published April 20, 2013

Citation: Khan AH (2013) Surgical Infections \& Rule of Antibiotics. Trop Med Surg 1: 116. doi:10.4172/2329-9088.1000116

Copyright: (c) $2013 \mathrm{Khan} \mathrm{AH}$. This is an open-access article distributed under the terms of the Creative Commons Attribution License, which permits unrestricted use, distribution, and reproduction in any medium, provided the original author and source are credited. 
was additionally independent of preoperative patient risk. Therefore, it should be clarified that one cannot determine actual economical impact simply by direct cost analysis methods. Professionals working on health economic policy need to design special research projects that should include outcomes, and direct and indirect costs procedures to evaluate inappropriate antibiotic usage in hospitals.

The inappropriate preoperative use of antibiotics also consumes a significant portion of hospital pharmacy's expenses for antibiotics. Healthcare professionals are needed to be encouraged to reduce antibiotics usage for prophylaxis in unfortunate settings. This objective could be achieved either by educational programs or by guidelines implementation.

\section{References}

1. Andersen BR, Kallehave FL, Andersen HK (2005) Antibiotics versus placebo for prevention of postoperative infection after appendicectomy. Cochrane Database Syst Rev : CD001439.

2. Craig WA, Uman SJ, Shaw WR, Ramgopal V, Eagan LL, et al. (1978) Hospital use of antimicrobial drugs. Survey at 19 hospitals and results of antimicrobial control program. Ann Intern Med 89: 793-795.

3. Roberts AW, Visconti JA (1972) The rational and irrational use of systemic antimicrobial drugs. Am J Hosp Pharm 29: 828-834.

4. Song F, Glenny AM (1998) Antimicrobial prophylaxis in colorectal surgery: a systematic review of randomized controlled trials. Br J Surg 85: 1232-1241.

5. Gul YA, Lian LH, Jabar FM, Moissinac K (2002) Antibiotic prophylaxis in elective colorectal surgery. ANZ J Surg 72: 275-278.

6. Dellinger EP, Gross PA, Barrett TL, Krause PJ, Martone WJ, et al. (1994) Quality standard for antimicrobial prophylaxis in surgical procedures. Infectious Diseases Society of America. Clin Infect Dis 18: 422-427.

7. Gyssens IC, Geerligs IE, Nannini-Bergman MG, Knape JT, Hekster YA, et al. (1996) Optimizing the timing of antimicrobial prophylaxis in surgery: an intervention study. J Antimicrob Chemother 38: 301-308.

8. Bedouch P, Labarère J, Chirpaz E, Allenet B, Lepape A, et al. (2004) Compliance with guidelines on antibiotic prophylaxis in total hip replacement surgery: results of a retrospective study of 416 patients in a teaching hospital. Infect Control Hosp Epidemiol 25: 302-307.

9. Dahms RA, Johnson EM, Statz CL, Lee JT, Dunn DL, et al. (1998) Thirdgeneration cephalosporins and vancomycin as risk factors for postoperative vancomycin-resistant enterococcus infection. Arch Surg 133: 1343-1346.

10. Hale DA, Molloy M, Pearl RH, Schutt DC, Jaques DP (1997) Appendectomy: a contemporary appraisal. Ann Surg 225: 252-261.

11. Koch A, Zippel R, Marusch F, Schmidt U, Gastinger I, et al. (2000) Prospective multicenter study of antibiotic prophylaxis in operative treatment of appendicitis. Dig Surg 17: 370-378.

12. Lau WY, Fan ST, Chu KW, Suen HC, Yiu TF, et al. (1985) Randomized, prospective, and double-blind trial of new beta-lactams in the treatment of appendicitis. Antimicrob Agents Chemother 28: 639-642.

13. Söderquist-Elinder C, Hirsch K, Bergdahl S, Rutqvist J, Frenckner B (1995) Prophylactic antibiotics in uncomplicated appendicitis during childhood--a prospective randomised study. Eur J Pediatr Surg 5: 282-285.

14. Tönz M, Schmid P, Kaiser G (2000) Antibiotic prophylaxis for appendectomy in children: critical appraisal. World J Surg 24: 995-998.

15. Charalambous CP, Tryfonidis M, Swindell R, Lipsett AP (2003) When should old therapies be abandoned? A modern look at old studies on topical ampicillin. J Infect 47: 203-209.

16. Lau WY, Fan ST, Chu KW, Yip WC Yiu TF, et al. (1986) Cefoxitin versus gentamicin and metronidazole in prevention of post-appendicectomy sepsis: a randomized, prospective trial. J Antimicrob Chemother 18: 613-619.
17. al-Dhohayan A, al-Sebayl M, Shibl A, al-Eshalwy S, Kattan K, et al. (1993) Comparative study of augmentin versus metronidazole/gentamicin in the prevention of infections after appendicectomy. Eur Surg Res 25: 60-64.

18. Bratzler DW, Hunt DR (2006) The surgical infection prevention and surgical care improvement projects: national initiatives to improve outcomes for patients having surgery. Clin Infect Dis 43: 322-330.

19. Plowman $R$ (2000) The socio-economic burden of hospital-acquired infection London: Public Health Laboratory Service.

20. Coello R, Glenister H, Fereres J, Bartlett C, Leigh D, et al. (1993) The cost of infection in surgical patients: a case-control study. J Hosp Infect 25: 239-250.

21. Lynch W, Malek M, Davey PG, Byrne DJ, Napier A (1992) Costing wound infection in a Scottish hospital. Pharmacoeconomics 2: 163-170.

22. Lim VK, Cheong YM, Suleiman AB (1994) The use of surgical antibiotic prophylaxis in seven Malaysian hospitals. Southeast Asian J Trop Med Public Health 25: 698-701.

23. Ministry of Health $(\mathrm{MOH})$, Malaysia.Rational use of antibiotics; Clinical Practice Guidelines 1996. Academy of Medicine of Malaysia and Ministry of Health Malaysia. "http://www.acadmed.org.my/htmllindex.shtml"http:I/www.acadmed. org.my/htmllindex.shtml [accessed 8 February 2013]

24. Mazza A (2000) Ceftriaxone as short-term antibiotic prophylaxis in orthopedic surgery: a cost-benefit analysis involving 808 patients. J Chemother 12 Supp 3. 29-33.

25. Williams DN, Gustilo RB (1984) The use of preventive antibiotics in orthopaedic surgery. Clin Orthop Relat Res: 83-88.

26. Yeap JS, Lim JW, Vergis M, Au Yeung PS, Chiu CK, et al. (2006) Prophylactic antibiotics in orthopaedic surgery: guidelines and practice. Med J Malaysia 61 181-188.

27. Dimick JB, Chen SL, Taheri PA, Henderson WG, Khuri SF, et al. (2004) Hospita costs associated with surgical complications: a report from the private-sector National Surgical Quality Improvement Program. J Am Coll Surg 199: 531-537.

28. Roach AC, Kernodle DS, Kaiser AB (1990) Selecting cost-effective antimicrobia prophylaxis in surgery: are we getting what we pay for? DICP 24: 183-185.

29. Zhan C, Miller MR (2003) Excess length of stay, charges, and mortality attributable to medical injuries during hospitalization. JAMA 290: 1868-1874.

30. Khuri SF, Henderson WG, DePalma RG, Mosca C, Healey NA, et al. (2005) Determinants of long-term survival after major surgery and the adverse effect of postoperative complications. Ann Surg 242: 326-341. 